\title{
EVALUATION OF HIGH TEMPERATURE RESISTANCE OF THREE-LAYER HONEYCOMB PANEL PRODUCED FROM YUIPM-1200 ALLOY BY VACUUM DIFFUSION WELDING
}

\author{
I.A. GUSAROVA ${ }^{1}$, M. PARKO ${ }^{2}$, A.M. POTAPOV ${ }^{1}$, YU.V. FALCHENKO ${ }^{3}$, L.V. PETRUSHINETS ${ }^{3}$, \\ T.V. MELNICHENKO ${ }^{3}$ and V.E. FEDORCHUK ${ }^{3}$ \\ ${ }^{1} \mathrm{SC}$ «M.K. Yangel Design Bureau «Yuzhnoje» \\ 3 Krivorozhskaya Str., 49008, Dniepr, Ukraine. E-mail: infor@yuzhnoye.com \\ ${ }^{2}$ TECNALIA, Parque Tecnolygico de San Sebastian Mikeletegi Pasealekua \\ 2 E-20009 Donostia-San Sebastian-Gipuzkoa, Spain. E-mail: maria.parco@tecnalia.com \\ ${ }^{3}$ E.O. Paton Electric Welding Institute, NASU \\ 11 Kazimir Malevich Str., 03680, Kiev, Ukraine. E-mail: office@paton.kiev.ua
}

\begin{abstract}
Development of thermal protection systems is one of the important engineering problems that should be solved at development of reusable space vehicles. Metal panels of thermal protection systems should consist of separate tiles with individual fastening to load-carrying structure of space vehicle, with surface density of not more than $10 \mathrm{~kg} / \mathrm{m}^{2}$, capable of withstanding multiple long flights and providing temperature lowering from $1100{ }^{\circ} \mathrm{C}$ on the outer wall to $200{ }^{\circ} \mathrm{C}$ on the inner wall. The work shows the results on development of the technology of vacuum diffusion welding of a three-layer honeycomb panel from experimental powder alloy YuIPM-1200. Technological samples of three-layer honeycomb panel were made from this alloy, and their testing was performed in the working temperature range. 7 Ref., 11 Figures.
\end{abstract}

Key w or d s : thermal protection systems; metal three-layer panel, powder high-temperature alloy, vacuum diffusion welding, thermal cycling tests

Development of thermal protection systems with outer metal three-layer panel for reusable space vehicles has been conducted in the USA and Europe starting from the middle of the XXth century. So far, however, there is no information about their development for the windward hull of reusable space vehicles, preserving their performance at service loads for the required number of launches [1]. Development of such thermal protection will allow creation of a reliable reusable space vehicle (RSV) and reducing the cost of taking payloads to orbit.

In Ukraine (SC «DB «Yuzhnoje») developed a removable multilayer thermal protection structure (TPS) with outer metal three-layer panel, consisting of separate tiles with individual fastening to vehicle load-carrying structure, of not more than $10 \mathrm{~kg} / \mathrm{m}^{2}$ density, capable of withstanding multiple long flights and providing temperature lowering from $1100^{\circ} \mathrm{C}$ on the outer wall to $200{ }^{\circ} \mathrm{C}$ on the inner wall [2]. Schematic of TPS with metal outer three-layer panel with U-shaped butt joint and plate thermal insulation is shown in Figure 1. Metal outer three-layer panel with plane dimensions of $300 \times 300 \mathrm{~mm}$ consists of upper skin $0.5 \mathrm{~mm}$ thick, honeycomb core and lower skin $0.1 \mathrm{~mm}$ thick.
Special high-temperature powder alloy YuIPM-1200 based on Ni-Cr was developed for fabrication of outer metal structure. The alloy has the required level of emissivity and is resistant to oxidizing medium at superhigh temperatures that allows eliminating special coatings [3].

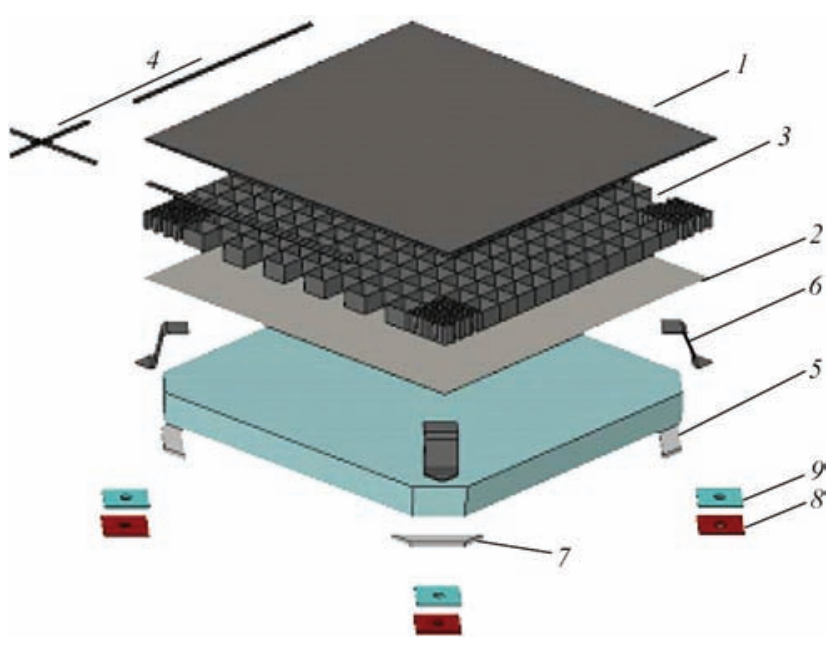

Figure 1. General view of TPS tile: 1 - panel upper skin; 2 panel lower skin; 3 - honeycomb core; 4 - U-shaped stampings; 5 - thermal insulation; $6-\mathrm{Z}$-shaped metal posts of fastening system; 7 - felt substrate; 8 - damping gasket from heat-resistant rubber; 9 - thermostat 

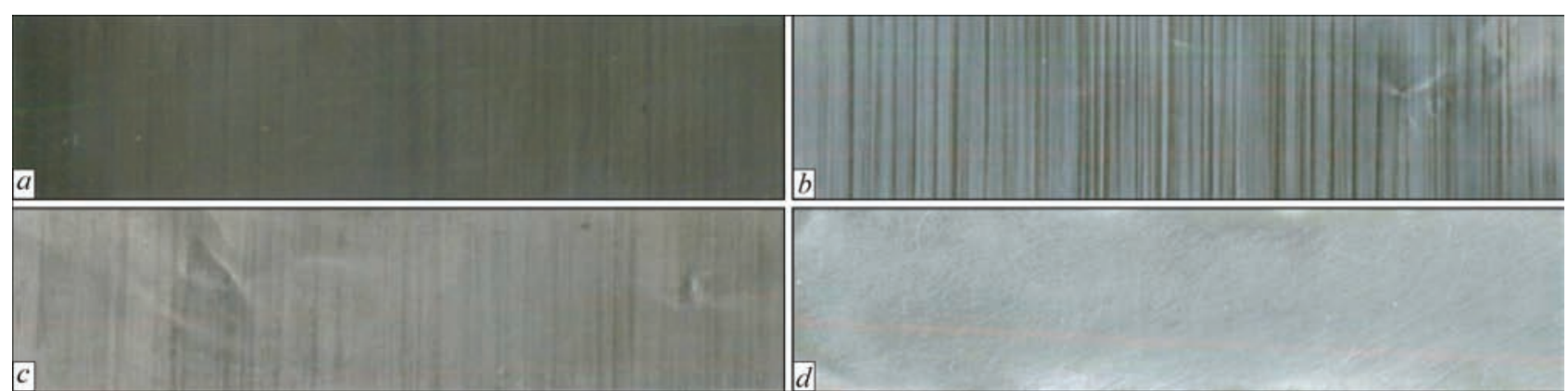

Figure 2. Appearance of the surface of foil from Ni-Cr high-temperature alloy YuIMP-1200; $a$ - appearance of foil in as-delivered state; $b$ - chemical etching in the following solution: $500 \mathrm{ml} \mathrm{HNO}_{3}, 250 \mathrm{ml} \mathrm{H}_{2} \mathrm{SO}_{4}, 10 \mathrm{~g} \mathrm{NaCl} ; c$ - chemical etching in the solution of $750 \mathrm{ml} \mathrm{HCl}, 250 \mathrm{ml} \mathrm{HNO}_{3}$; $d$ - mechanical cleaning with sandpaper with R1000 grain size

As the developed high-temperature powder alloy YuIPM-1200 based on Ni-Cr has practically no analogs, development of the technology of manufacturing three-layer panel with honeycomb core and making its engineering mock-up is of interest.

As available equipment allows welding parts of up to $200 \mathrm{~mm}$ size, the objective of this work was manufacturing the engineering mock-up of metal three-layer panel from YuIPM-1200 alloy of $150 \times 150 \mathrm{~mm}$ size and conducting experimental studies of TPS mock-up performance at thermal cycling in the working temperature range.

Technological process of manufacturing three-layer panel mock-up includes the following operations [4]:

- skin manufacturing;

- manufacturing blanks for honeycomb core;

- forming profiled strips from the blanks;

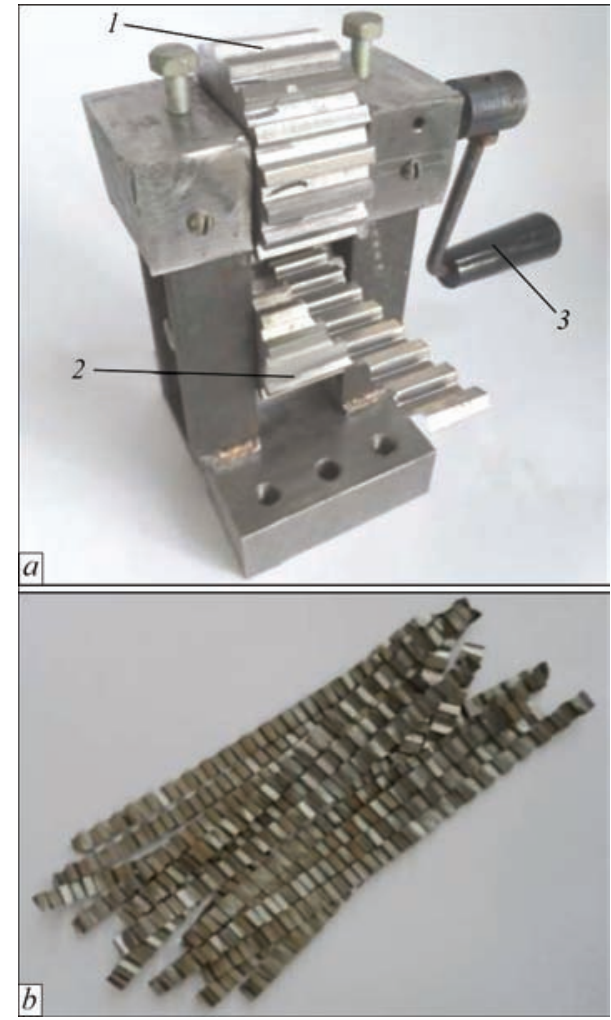

Figure 3. Device for strip forming (a) and profiled strip (b) (for description of $1-3$ see the text)
- welding the honeycomb core;

- manufacturing three-layer panels.

Manufacturing skins and foil for honeycomb core of required thickness was conducted by rolling by specially developed technology in SPC «Rubin».

In the initial as-rolled state the surface of foil from YuIPM-1200 alloy is covered by a dense oxide film (Figure 2,a). The possibility of application of chemical or mechanical cleaning for its removal was considered.

The following chemical solutions were used to remove the oxide film from foil surface: $500 \mathrm{ml} \mathrm{HNO}_{3}+$ $50 \mathrm{ml} \mathrm{H}_{2} \mathrm{SO}_{4}+10 \mathrm{~g} \mathrm{NaCl}$ or $750 \mathrm{ml} \mathrm{HCl}+250 \mathrm{ml}$ $\mathrm{HNO}_{3}$ [5]. Analysis of the state of foil surface after chemical etching showed that its complete cleaning does not take place (Figure 2, b, c).

Mechanical cleaning of foil using fine grain sandpaper R1000 allows producing a cleaner surface, compared to treatment in chemical solutions (Figure $2, d$ ). Foil cleaning with sandpaper allows eliminating defects found on its surface, which were due to unevenness of the surface of rolls used in its manufacture. Foil surface does not have any contamination or discoloration. Further on, removal of oxide film from foil surface was conducted by the method of mechanical cleaning. After cleaning, the foil was rinsed in water to remove fine dust particles and dried in air for $20-30 \mathrm{~min}$ at the temperature of $30-40{ }^{\circ} \mathrm{C}$. Foil cutting up to ensure the required accuracy of sample length and absence of tears or burrs was conducted in keeping with GOST 618-73.

Method of rolling in profiled rollers which allows producing corrugated strips with a high precision, became widely applied for manufacturing honeycomb structures [6]. In this connection, a special device was designed and manufactured to form profiled strip of honeycomb core (Figure 3,a).

The device consists of two gears 1 and 2 with teeth parameters corresponding to honeycomb cell size. Driving wheel 1 is mounted on one axle with handle 3 , 


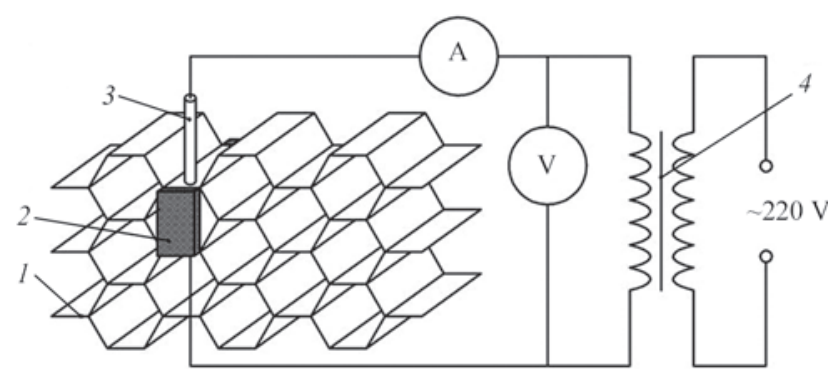

Figure 4. Schematic of a device for welding honeycomb core from $\mathrm{Ni}-\mathrm{Cr}$ alloy: 1 - profiled strips; 2 - graphite electrode; 3 - copper electrode; 4 - transformer

setting the device into motion. Appearance of formed strip of honeycomb core is given in Figure 3, $b$.

As shown by investigations, foil from YuIPM-1200 alloy in as-delivered condition has considerable work hardening, due to its rolling. At manufacture of honeycomb core strip cracking occurred in a number of cases in the points of foil bending, which was caused by a change of material properties through work-hardening.

It is known [7] that application of heat treatment in the temperature range of $0.35-0.40$ of the alloy melting temperature allows its ductility to be increased.

It is also established than vacuum annealing for 20-30 min at the temperature of $780-800{ }^{\circ} \mathrm{C}$ is sufficient to relieve work-hardening of the studied alloy. After this heat treatment alloy ductility increases, that allows preventing cracks at forming of honeycomb core cells.

Spot welding was used to produce honeycomb core from profiled strips (Figure 4). Profiled strip surfaces were degreased in alcohol before their assembly into blocks. Strips 1 were mounted on graphite electrode 2, which was made proceeding from overall dimensions of honeycomb cells (Figure 4). After compression of metal sections to be welded, current was passed through electrode 3. Optimum parameters of the process for this foil thickness are current

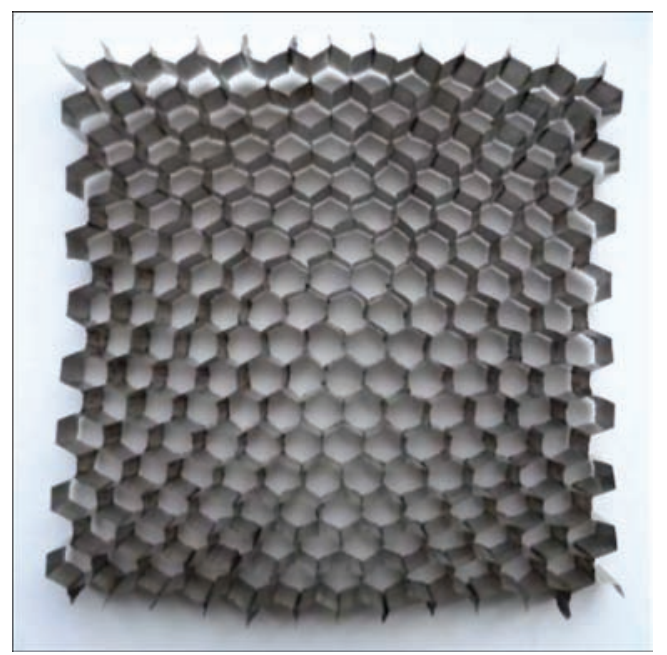

Figure 5. Honeycomb core made from foil of YuIPM-1200 alloy

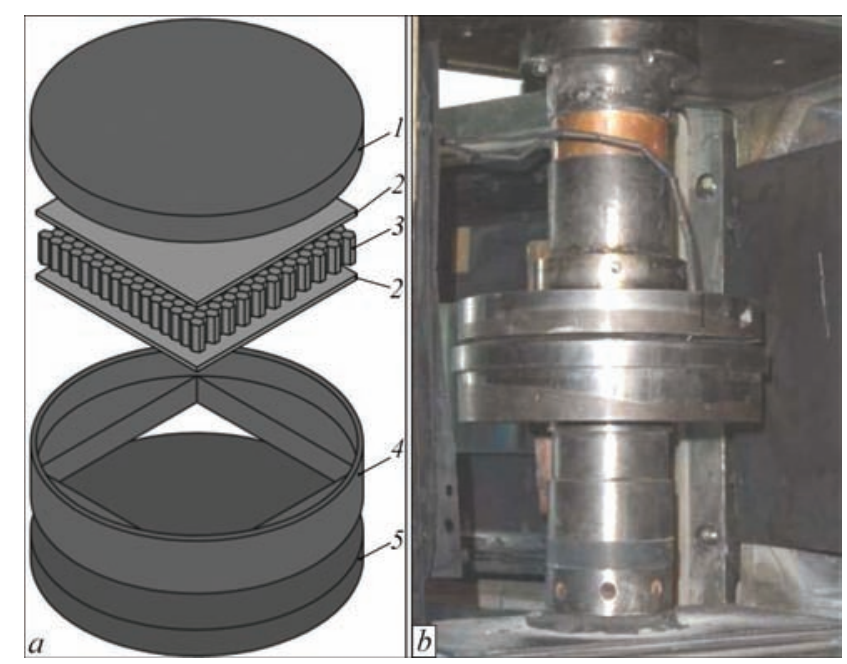

Figure 6. Schematic of fixture for welding three-layer honeycomb panels $(a)$ and working chamber with the fixture mounted in it (b): 1 - upper flange; 2 - skin; 3 - honeycomb; 4 - limiting sleeve; 5 - lower flange

$I=300 \mathrm{~mA}$, voltage $U=5 \mathrm{~V}$ at $2 \mathrm{~mm}$ diameter of copper electrode. Appearance of honeycomb core package of $150 \times 150 \mathrm{~mm}$ size from YuIPM-1200 alloy based on Ni-Cr is shown in Figure 5.

It is experimentally established that the best conditions for welding YuIPM-1200 alloy are provided by

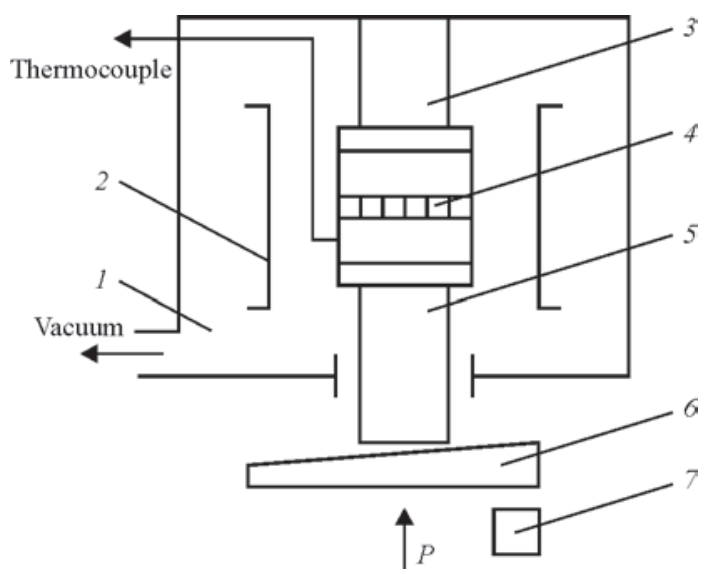

Figure 7. Schematic of working chamber with fixture: 1 - working chamber; 2 - molybdenum heater; 3 - upper rod; 4 three-layer panel mounted in limiting sleeve; 5 - lower rod; 6 wedge; 7 - press

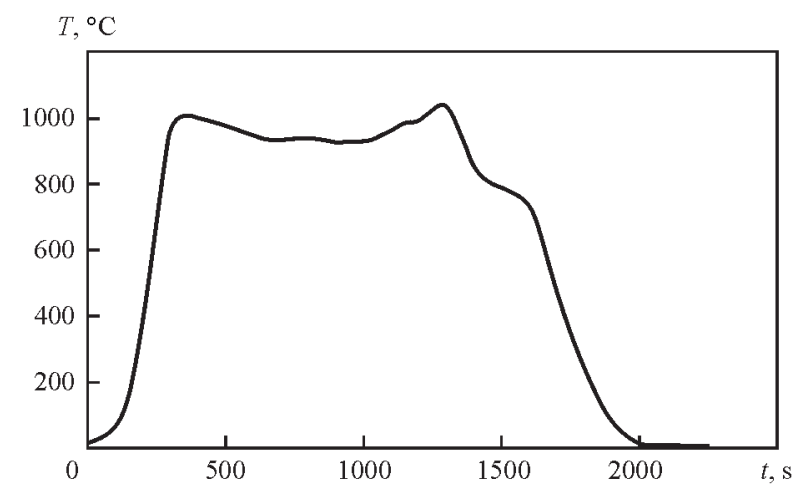

Figure 8. Dependence of temperature on TPS outer surface on time 


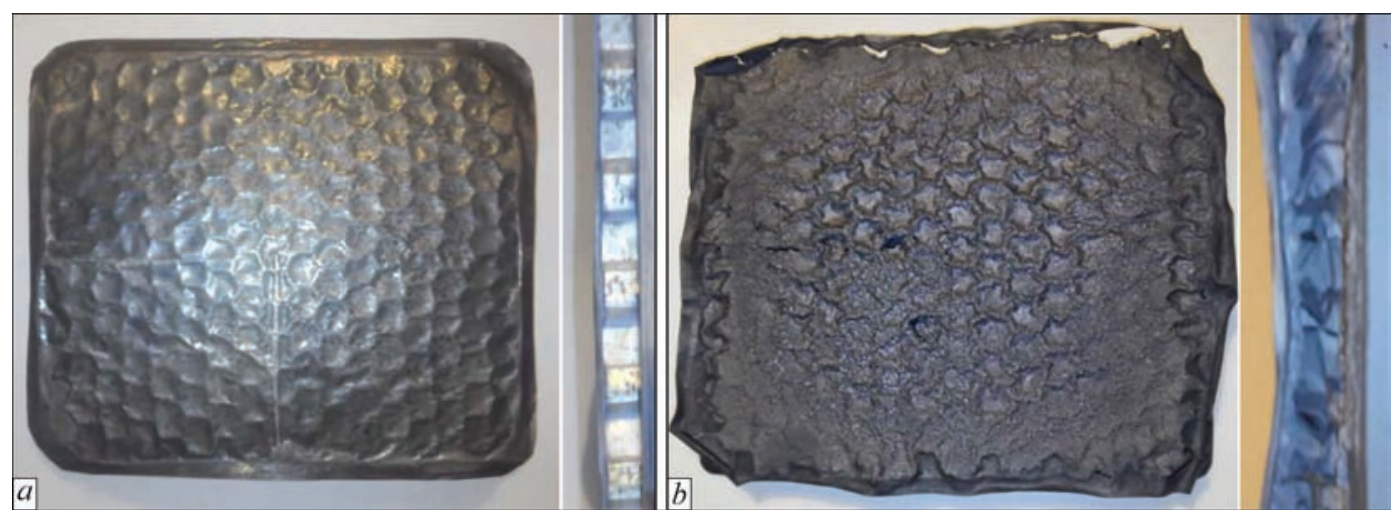

Figure 9. Appearance of three-layer panel before ( $a$ ) and after testing (b)

application of upper electrode from copper and lower electrode from graphite that eliminates undesirable adhesion of foil surface to the electrodes. Welding was followed by grinding of end faces of the honeycomb core.

Vacuum diffusion welding was used for joining the honeycomb core and skins into a three-layer structure. Welding was conducted in a specially designed and manufactured fixture (Figure 6). In terms of design, the device (fixture) for three-layer panel welding consists of the lower and upper flanges and limiting sleeve (Figure 6,a). During welding, flanges ensure pressing of skins to honeycomb core over the entire area of contact, and limiting sleeve allows equalizing the temperature field in the item being welded. Figure $6, b$ shows the appearance of the fixture for welding a three-layer honeycomb panel in the vacuum chamber of diffusion welding unit.

Figure 7 shows the schematic of working chamber of diffusion welding unit with the fixture installed in it. The possibility of placing a thermocouple in the fixture was envisaged for welding temperature control. Pressure was applied to the part being welded from the press through wedge 6 and lower rod 5 . Pressure magnitude was evaluated by a dynamometer.

Heating of the fixture with three-layer honeycomb panel mounted in it, was conducted at the rate of 25 $30{ }^{\circ} \mathrm{C} / \mathrm{min}$, and after reaching the welding temperature, pressure was applied to it. Soaking at welding temperature was conducted for $25-30 \mathrm{~min}$. After that

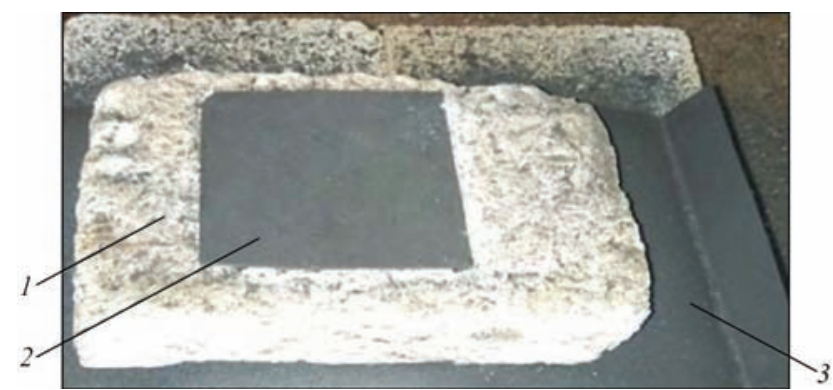

Figure 10. Sample in thermal insulation cell: 1 - thermal insulation cell; 2 - outer skin of three-layer metal TPS; 3 - tray for loading into the furnace the applied pressure level was lowered to zero, and cooling to room temperature was performed under vacuum.

Thus, engineering samples of three-layer honeycomb panel mock-up of $150 \times 150 \mathrm{~mm}$ size were produced, which were used for experimental studies. Thickness of upper skin of three-layer honeycomb panel was $0.5 \mathrm{~mm}$, that of lower skin was $0.1 \mathrm{~mm}$, honeycomb core was made from foil $0.03 \mathrm{~mm}$ thick.

Temperature modes of heating and cooling of the studied samples were selected proceeding from theoretical temperature curve on the structure surface during RSV descent (Figure 8).

Maximum working temperatures on the surface of a three-layer honeycomb panel are equal to $1100{ }^{\circ} \mathrm{C}$. To improve structure reliability, a $10 \%$ margin of high-temperature strength is incorporated into their design. Therefore, the first stage was optimization of test procedure and determination of structure performance at one-time exposure to the temperature of $1200{ }^{\circ} \mathrm{C}$.

Testing an engineering sample of three-layer panel was conducted, using «SNOL» laboratory furnace. Before the start of testing, the furnace was heated up to the temperature of $1210^{\circ} \mathrm{C}$, which was followed by placing the sample into the furnace with lower skin $0.1 \mathrm{~mm}$ thick facing upwards, and upper skin $0.5 \mathrm{~mm}$ thick resting on the furnace lower wall. Soaking of three-layer panel mock-up in the furnace for $20 \mathrm{~min}$, at the temperature of $1200{ }^{\circ} \mathrm{C}$ was performed. Then, the sample was removed and cooled to the temperature in the premises. Cooling time was $3 \mathrm{~min}$.

Appearance of the studied sample before and after testing is given in Figure 9. Upper skin $0.5 \mathrm{~mm}$ thick preserved its intactness. Skin $0.1 \mathrm{~mm}$ thick deformed during cooling in the points of welding to the honeycombs, and through-thickness cracks formed in it in several places. After complete cooling of the mock-up to temperature in the premises, $0.1 \mathrm{~mm}$ thick skin became brittle, honeycomb faces lost their stability and strength in the transverse direction. 

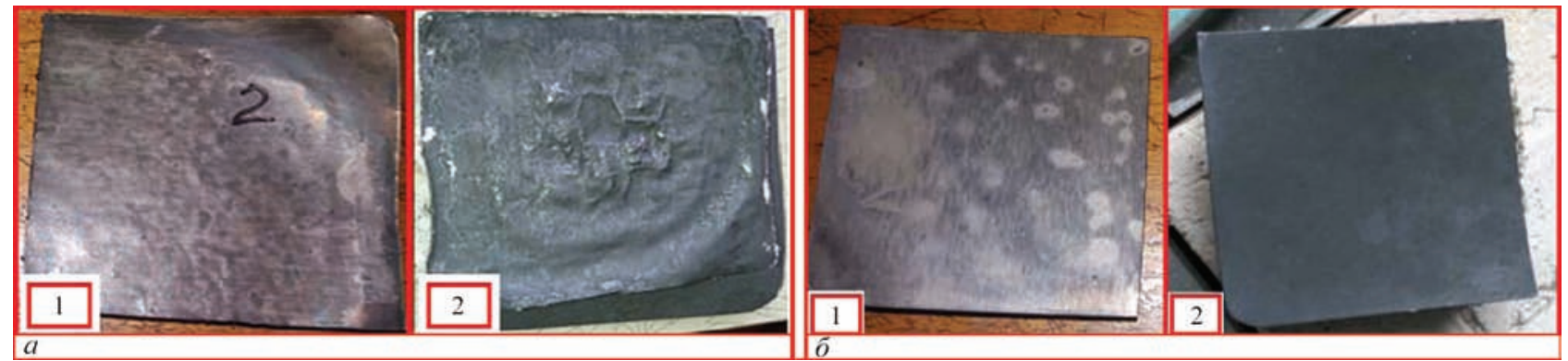

Figure 11. Appearance of mock-up lower ( $a$ ) and upper (b) skins before thermal cycling (1) and after 11 thermal cycles (2)

As thin-layered elements of the structure of $0.03 \mathrm{~mm}$ (honeycombs) and $0.1 \mathrm{~mm}$ (lower skin) thickness fail under the impact of $1200{ }^{\circ} \mathrm{C}$ for $20 \mathrm{~min}$, thermal cycling of the next sample was conducted in the standard temperature range of $20-1100{ }^{\circ} \mathrm{C}$. To model standard service conditions the sample was placed into a special thermal protection cell from ceramic fibre, which ensured end face insulation from the impact of direct heat flows, and also modeled TPS inner thermal insulation located under the panel lower skin (Figure 10). Number of thermal cycles at testing was determined by structure integrity at visual examination of three-layer outer panel mock-up after each thermal cycle.

Before the start of testing the furnace was heated to the temperature of $1150^{\circ} \mathrm{C}$. After that the sample was placed into the furnace and was soaked for $20 \mathrm{~min}$ at the temperature of $1100^{\circ} \mathrm{C}$. The sample was taken out together with thermal insulation cell and cooled to the temperature in the premises $\left(15^{\circ} \mathrm{C}\right)$ in $11 \mathrm{~min}$, that corresponds to the time of cooling of the vehicle outer surface, obtained at theoretical calculations (Figure 8).

After the first thermal cycle, a protective oxide film of dark-grey colour formed on sample surface. The honeycombs deformed.

After the fifth thermal cycle, the lower skin of three-layer metal thermal protection $0.1 \mathrm{~mm}$ thick deformed. Residual deformations remained after cooling. After $11^{\text {th }}$ thermal cycle through-thickness defects $5 \mathrm{~mm}$ long along honeycomb faces were found in the point of joining with the honeycomb core (Figure 11, a). Panel upper skin $0.5 \mathrm{~mm}$ thick did not show any visible changes of shape or dimensions (Figure 11, b).
Thus, thermal cycling of a mock-up of three-layer outer panel of thermal protection structure from YuIPM-1200 alloy in the working temperature range showed that the structural elements $0.5 \mathrm{~mm}$ thick preserve their serviceability for 11 thermal cycles in the set mode. Thinner elements of the structure deform and fail after thermal cycling.

To ensure normal functioning of the structure at standard heat flows, it is necessary to increase the thickness of structural elements (more than $0.1 \mathrm{~mm}$ ) and adjust the parameters of welding the three-layer structures.

Work was performed under project LightTPS FP7 \# 607162 .

1. Tumino, G. (2002) European development and qualification status and challenges in hot structures and thermal protection systems for space transportation concepts. In: Proc. of $4^{\text {th }}$ Europ. Workshop on Hot Structures and Thermal Protection Systems for Space Vehicles (Palermo, Italy, 26-29 Nov. 2002). Paris: Europ. Space Agency, 2003, 39-43.

2. Potapov, A.M., Shevtsov, E.I., Tikhy, V.G. et al. Multilayer thermal protection system of reusable space vehicle. Pat. 91891 Ukraine. Int. Cl. B64G 1/58, B64C 1/38, B64C 3/36. Fil. 25.11.2013. Publ. 25.07.2014.

3. Skorokhod, V.V., Solntsev, V.P., Frolov, G.A. et al. Method of producing of heat-resistant nickel-chrome based alloy. Pat. 108096 Ukraine. Int. Cl. C22C 19/05, B22F 3/16, B22F 3/12, B22F/00. Fil. 09.10.2012. Publ. 27.01.2014.

4. Bitzer, T.N. (1997) Honeycomb technology. Materials, design, manufacturing, applications and testing. New York: Chapman \& Hall.

5. Baranova, L.V., Demina, E.L. (1986) Metallographic etching of metals and alloys: Refer. Book. Moscow: Metallurgiya.

6. Qiuming Zhang, Xiaodong He. (2009) Microstructural evolution and mechanical properties of a nickel-based honeycomb sandwich. Materials Characterization, 60(3), 178-182.

7. Gorelik, S.S. (1978) Resolidification of metals and alloys. Moscow: Metallurgiya. 